\title{
El estándar de la reparación integral en la jurisprudencia de la Corte Constitucional
}

Pamela Aguirre Castro*

Pablo Alarcón Peña**

\section{RESUMEN}

El presente estudio aborda el estado del arte del concepto y alcance de la reparación integral en el constitucionalismo ecuatoriano, particularmente desde su reconocimiento inédito y expreso en el texto de la Constitución 2008. Para ello se inicia con un análisis del concepto y alcance de la reparación integral desde la norma constitucional. En un segundo momento, siendo el eje central de este análisis, se evalúa desde la dimensión sociológica-jurisprudencial, el desarrollo que ha tenido la reparación integral en el discurso judicial impuesto por la Corte Constitucional del Ecuador en sus decisiones. Para el efecto, luego de una indagación en el compendio jurisprudencial constante en las bases de datos y publicaciones de la Corte Constitucional, se han seleccionado a aquellas decisiones que revisten un análisis constitucional y convencional pormenorizado en torno a la naturaleza y alcance de la reparación integral. Como consecuencia de este análisis, desde la realidad y particularismos que se reflejan en la jurisprudencia de la Corte, se plantean algunas reflexiones en torno a la importancia sustancial que reviste la reparación integral para alcanzar la tutela efectiva de los derechos constitucionales. Palabras CLAVE: reparación integral, Constitución 2008, jurisprudencia constitucional.

\section{ABSTRACT}

This paper seeks to illustrate integral reparation effectiveness in ecuadorian constitutionalism. It begins with an analysis beyond the concept and scope of integral reparation provided in the constitutional norm. In a second moment, from the sociological-jurisprudential dimension, the paper treats integral reparation development in the judicial discourse that has been imposed by the Ecuadorian Constitutional Court in its binding decisions. As a consequence of this analysis, some

* Abogada de la Corte Interamericana de Derechos Humanos.

** Asesor de la Corte Constitucional del Ecuador. 
reflections are proposed tending to contribute to integral reparation in judicial decisions.

KEYWORDS: Integral reparation, Constitution 2008, constitutional jurisprudence.

\section{INTRODUCCIÓN}

$\mathrm{E}$ n la Constitución de 2008 existe una constante referencia a la reparación integral. ${ }^{1}$ Esto obedece a dos circunstancias en particular en materia de justiciabilidad de los derechos constitucionales. La primera de ellas es que fue la Constitución 2008 la que reconoció de manera expresa e inédita, en su artículo 86 número 3, el concepto y alcance de la reparación integral en materia de garantías jurisdiccionales, a partir de lo cual la declaración de vulneración de un derecho lleva necesariamente la reparación integral del derecho conculcado. La segunda razón, consecuente con la primera, es la recepción de los estándares internaciones de los derechos humanos en nuestra Norma Suprema, ${ }^{2}$ específicamente estándares internacionales respecto a la restitutio in integrum, razón por la cual conocer el discurso judicial existente respecto a ella se torna fundamental para tener el panorama claro respecto a la efectividad de las garantías de los derechos.

En cuanto a su reconocimiento expreso en la Constitución 2008, cabe señalar que esta positivización guarda una relación proporcional con los cambios sustanciales que también sufrieron las garantías jurisdiccionales con relación a aquellas existentes en el año 1998. Así, por ejemplo, entre los cambios principales está la naturaleza de las

1. "la reparación integral en el ordenamiento ecuatoriano constituye un verdadero derecho constitucional, cuyo titular es toda persona que se considere afectada por la vulneración de sus derechos reconocidos en la Constitución. Adicionalmente, es un principio orientador que complementa y perfecciona la garantía de los derechos; así, esta institución jurídica se halla inmersa en todo el ordenamiento constitucional ecuatoriano, siendo transversal al ejercicio de los derechos; así por ejemplo, la obligatoriedad de la reparación para las víctimas de delitos penales (artículo 78); para los consumidores y consumidoras que sufran engaños comerciales (artículo 52); la posibilidad de demandar una reparación como consecuencia de las afectaciones por racismo o xenofobia contra comunidades o poblaciones indígenas (artículo 57) y por afectaciones ambientales que puedan atentar contra los ecosistemas (artículo 397), entre otras". Corte Constitucional del Ecuador, sentencia 004-13-SAN-CC.

2. Pamela Aguirre, "El control de convencionalidad y sus desafíos en el Ecuador", Revista del Instituto Interamericano de Derechos Humanos (IIDH), No. 64. Disponible en 〈http://www.iidh.ed.cr/iidh/media/4759/revista-64-2web.pdf〉. 
nuevas garantías, mecanismos propiamente jurisdiccionales, de conocimiento, las que dejan atrás una concepción meramente cautelar. En efecto, el carácter cautelar de las garantías previstas en la Constitución de 1998, no permitían que juezas y jueces puedan declarar vulneraciones a derechos constitucionales y, en consecuencia, que puedan reparar integralmente. Estas limitaciones y déficits, que claramente tenían impactos en el ámbito material de protección de aquellas garantías, fueron enmendadas, confiriendo al juez constitucional un rol protagónico en la tutela judicial efectiva de los derechos constitucionales objeto de vulneraciones. ${ }^{3}$

Por esta razón el presente estudio concentra su atención en indagar y proponer reflexiones en torno a la naturaleza y el alcance de esta reparación integral desde la vigencia de la Constitución 2008, en la dimensión sociológica.

Cabe precisar que cuando nos referimos al análisis de la reparación integral desde la vigencia de nuestra Constitución 2008, lo hacemos desde una concepción anti formalista y amplia, es decir, nuestro análisis no se ciñe al análisis descriptivo de las normas constitucionales que reconocen a esta institución, sino principalmente a la forma cómo esta ha sido entendida por el órgano autorizado para interpretarla con carácter objetivo.

Es así que, sin descuidar el componente doctrinario o teórico, los principales aportes de esta investigación se construirán desde el análisis de los particularismos que se advierten en la jurisprudencia constitucional relevante emitida por la Corte Constitucional, y que en definitiva mostrarán cómo está operando esta institución en la práctica. Desde ahí, desde la dimensión sociológica, jurisprudencial, se aportará con planteamientos y reflexiones en torno al necesario desarrollo de ese concepto de reparación integral ecuatoriano, aquel que parte de la Constitución pero que centralmente se muestra en la práctica diaria del máximo órgano de justicia constitucional del país. Sus criterios vinculantes no solo obligan a los casos particulares que resuelven, sino que muchos de esos criterios interpretativos sirven de parámetros para la argumentación jurídica de todos los jueces del país.

3. "Es por esas razones que la reparación integral se configura como algo más que una institución del ordenamiento jurídico convirtiéndose en un principio del derecho, que debe estar presente en toda resolución judicial referente a la vulneración de derechos. Este principio de la reparación integral respalda y brinda materialidad a las garantías jurisdiccionales. Y ello, en tanto que a la declaración y reconocimiento de que el derecho ha sido quebrantado, añade el desagravio y el resarcimiento del derecho transgredido, situación que refleja la responsabilidad asumida por el agresor sobre al acto antijurídico y revela la intención por parte del aparato estatal de satisfacer completamente a la víctima". Claudia Storini y Marco Navas, $L a$ acción de protección en Ecuador: realidad jurídica y social (Quito: Corte Constitucional del Ecuador, 2013), 155 . 
Por ello, luego de una revisión de la base de datos de la Corte Constitucional, de sus publicaciones en la materia, se han seleccionado aquellas decisiones que en primer lugar tengan un efecto objetivo y que a su vez hayan desarrollado de manera pormenorizada, atendiendo al bloque de constitucionalidad y control de convencionalidad, el concepto, naturaleza y alcance de la reparación integral.

Resulta, entonces, sumamente necesario partir de un método deductivo, que considere las cláusulas constitucionales pertinentes, la doctrina más relevante para pasar al análisis particular, casuístico, en torno a la materia. Sin embargo de ello, nuestro mayor aporte se construirá desde el método inductivo, es decir, la teoría y las cláusulas constitucionales no serán el parámetro estándar desde el cual evaluaremos nuestra jurisprudencia; todo lo contrario, con la finalidad de construir un análisis crítico, lo que pretendemos es aportar a la construcción de teorías y conceptos locales, teorías que se encuentran centralmente en aquella dimensión sociológica de nuestro derecho y que no pueden no deben ser evaluadas desde teorías transnacionales.

Con esta aclaración metodológica podemos iniciar nuestro análisis. La reparación integral surge como consecuencia jurídica de la vulneración de un derecho por la que se exige a su vez la responsabilidad del agresor. Esta premisa permite afirmar inequívocamente que toda persona que se vea afectada en sus derechos ilegítimamente tiene derecho a exigir la reparación del daño. Este carácter de exigibilidad que impregna a la reparación integral la convierte en un derecho individual y colectivo, cuando deviene de la transgresión de un derecho humano/fundamental/constitucional. ${ }^{4}$

4. Sobre la concepción de derechos humanos, fundamentales y constitucionales, es importante anotar la evolución que estos han sufrido a partir de la Segunda Guerra Mundial cuando, a propósito de la Declaración de los Derechos Humanos de 1948, los Estados europeos (Alemania, Italia, España, Portugal, entre otros) y posteriormente los latinoamericanos (Brasil, Ecuador, Colombia, Venezuela, Bolivia), inician un proceso de incorporación de los derechos humanos en las Constituciones como normas verdaderamente jurídicas, plenamente exigibles, con garantías para hacerlos eficaces, de ahí que adoptan la denominación de derechos fundamentales. Subsiguiente una visión pro homine genera la incorporación de un criterio amplio de protección de la dignidad humana, y en consecuencia la exigibilidad ya no se limita a un catálogo de derechos, sino a todos estos; de ahí que, por ejemplo, la Constitución ecuatoriana de 2008 adopta el criterio de la doctrina de la unidad de la dignidad humana, disponiendo expresamente que todos los derechos gozan de igual jerarquía, son exigibles y justiciables. En efecto, “Art. 11.- [...] Todos los principios y los derechos son inalienables, irrenunciables, individuales, interdependientes y de igual jerarquía", de lo cual se deriva que en Ecuador no existe distinción entre derechos humanos/fundamentales/constitucionales, a diferencia de otros sistemas constitucionales que si distinguen entre derechos constitucionales y fundamentales, razón por la cual este estudio se refiere a ellos indistintamente como derechos constitucionales o, simplemente, derechos. Ello sin perjuicio de recordar que, con carácter general, se utiliza la expresión derechos humanos para referirse a la dimensión internacional de los derechos, derechos fundamentales para referirse a los derechos subjetivos dotados de "fundamentalidad" (por el rango de su reconocimiento, por sus especiales garantías, etc.) y derechos constitucionales para aludir a aquellos derechos fundamentales cuya fundamentalidad se deriva, precisamente, de estar recogidos en la Constitución. 
Así, en el contexto internacional se determina reiteradamente que "toda violación de derechos humanos hace nacer un derecho a la reparación a favor de la víctima, de sus parientes o compañeros y que implica el deber del Estado de reparar". ${ }^{5}$ En virtud de la significativa relevancia que representa en materia de derechos humanos, la reparación integral es también concebida como un principio rector de carácter internacional, situación que configura la proyección de su naturaleza jurídica en una doble dimensión.

La reparación integral contiene alcances más profundos respecto al proyecto de vida de las víctimas, en razón de que la afectación de derechos implica consecuencias de mayor magnitud en los ámbitos intangibles del ser humano, que no se limitan a una compensación económica. Es entonces que la estricta indemnización actúa de manera reparadora frente a daños civiles, mientras la reparación integral opera para enfrentar afectaciones más complejas provenientes de vulneraciones de derechos constitucionales. Y es que el daño debe ser entendido como todo menoscabo a las facultades jurídicas que tiene una persona para disfrutar un derecho constitucional. La responsabilidad jurídica es de naturaleza internacional cuando se incurre en ilícitos que son contrarios a las obligaciones reconocidas por el derecho internacional, compuesta por un elemento objetivo, es decir la violación positiva o negativa de una prescripción normativa del derecho internacional de derechos humanos y el elemento subjetivo que refiere la atribución de dicha conducta ilícita a un Estado.

A partir de esta breve introducción, en el presente trabajo ofreceremos, en primer lugar, la dimensión normativa de la reparación integral, en la Constitución de 2008, para luego pasar a revisar el desarrollo de las medidas de reparación integral ordenadas en el discurso judicial que ha impuesto la Corte Constitucional del Ecuador en sus decisiones, y finalizar con las reflexiones que ofrece el estudio.

\section{REPARACIÓN INTEGRAL EN EL VIGENTE MARCO CONSTITUCIONAL EN EL ECUADOR}

La reparación integral, como concepto básico de las decisiones constitucionales, ha tenido múltiples referencias, principalmente desde el derecho internacional de los

Sobre esta cuestión, véase Germán J. Bidart Campos, Teoría general de los derechos humanos (México D. F.: UNAM, 1989), 165 y s.

5. Javier Miranda, "Enfoques de Naciones Unidas sobre Impunidad y Reparación", en Verdad y Justicia en procesos de paz o transición a la democracia, Memorias (Bogotá: Oficina en Colombia del Alto Comisionado de las Naciones Unidad para los Derechos Humanos/Comisión Colombiana de Juristas/Fundación Social/Programa por la paz Compañía de Jesús, 2003), 83. 
derechos humanos, dado su objeto principal de tutela, la dignidad humana, las cuales han sido asimiladas en el plano normativo y jurisprudencial, por el Estado ecuatoriano a partir del cambio de modelo constitucional. ${ }^{6}$

Con su uso se pretende señalar la necesidad de reconocer como un derecho, el otorgamiento de medidas personales y materiales, mediante criterios objetivos para determinar la condición de víctima. Dicho concepto, como es conocido, en el contexto del trabajo de las Naciones Unidas, surgió cuando la Subcomisión de Prevención de Discriminaciones y Protección a las minorías decidió encargar un estudio sobre este derecho para elaborar sus principios y directrices básicos, lo cual resultaba apropiado en una época en que se buscaba una justicia de transición en varios países a finales de los años de $1980 .^{7}$

En los principios y directrices básicos sobre el derecho de las víctimas de violaciones manifiestas de normas internacionales de derechos humanos y del derecho internacional humanitario a interponer recursos y obtener reparaciones, que fueron aprobados por la Asamblea General de las Naciones Unidas, quince años después, se establecen diversas formas de reparación, que pueden resumirse en: restitución, indemnización, rehabilitación, satisfacción y garantías de no repetición. ${ }^{8}$

La reparación integral es una institución jurídica que tiene por objeto subsanar, en la medida de lo posible, las consecuencias reales y potenciales generadas a partir de la vulneración de un derecho, para que este sea reintegrado in integrum; de ahí que el artículo 86 número 3 de la Constitución de la República del Ecuador recoja la disposición que el juez, en caso de constatar la vulneración a derechos constitucionales y/o reconocidos en instrumentos internacionales de derechos humanos, declarará tal vulneración y ordenará la reparación integral, material e inmaterial, especificando las obligaciones positivas o negativas a cargo del destinatario de la decisión judicial. Es importante resaltar que la citada disposición resalta que los procesos judiciales en materia de garantías jurisdiccionales de protección de los derechos "Solo finalizarán con la ejecución integral de la sentencia o resolución".

Resulta entonces claro que la Norma Fundamental prevé en materia de garantías jurisdiccionales, en primer lugar, el derecho a la reparación integral de las víctimas de derechos humanos como una consecuencia de la transgresión de uno o varios de-

6. Constitución de la República del Ecuador (2008), art. 1.

7. Theo van Boven, "Principios y directrices básicos de las Naciones Unidas sobre el derecho de las víctimas de violaciones manifiestas de las normas internacionales de derechos humanos y de violaciones graves del Derecho Internacional Humanitario a interponer recursos y obtener reparaciones". Disponible en «http:// legal.un.org/avl/pdf/ha/ga_60-147/ga_60-147_s.pdf. Consulta: 28 de junio de 2017.

8. Asamblea General de las Naciones Unidas, Resolución 60/147, 16 de diciembre de 2005.

9. Constitución de la República del Ecuador (2008), art. 86, numeral 4. 
rechos constitucionales; $\mathrm{y}$, en segundo lugar, que solo culminará el proceso con una constatación de la ejecución de la reparación integral si se han declarado vulneraciones a derechos constitucionales; de este modo, las garantías de protección de los derechos solo son eficaces en la medida que las medidas de reparación integral sean ejecutadas de manera adecuada y oportuna.

En efecto, si el fin primigenio del Estado constitucional de derechos y justicia es asegurar el pleno ejercicio de los derechos de las personas y naturaleza, las garantías jurisdiccionales de protección de los derechos actúan como mecanismos de protección judicial, en los cuales la reparación integral es medular. Precisamente, en este sentido se ha generado el desarrollo infraconstitucional, Ley Orgánica de Garantías Jurisdiccionales y Control Constitucional -vigente desde el 22 de octubre de 2009(en adelante LOGJCC) norma adjetiva de la Constitución en materia de control constitucional y garantías jurisdiccionales de los derechos, al determinarse en el artículo 6 que el propósito esencial de las garantías jurisdiccionales es la protección eficaz e inmediata de los derechos reconocidos en la Constitución y en los instrumentos internacionales de los derechos humanos, la declaración de la transgresión de uno o varios y la reparación integral de los daños causados por la vulneración.

En esta misma línea, el artículo 17 de la LOGJCC, al establecer los requisitos mínimos que deben contener las sentencias emitidas en las decisiones de garantías jurisdiccionales, consagra la reparación integral como un elemento imprescindible del fallo constitucional, dado que la declaración de vulneración de uno o varios derechos constitucionales pierde sentido sin la correspondiente reparación integral a la víctima.

Se determina expresamente en el artículo 18 del mismo cuerpo normativo que "La reparación se realizará en función del tipo de violación, las circunstancias de los hechos y la afectación al proyecto de vida", con lo cual la reparación integral debe ser fruto de la motivación del juzgador constitucional, considerando como principal elemento la proporcionalidad que debe existir entre los remedios jurídicos y la declaratoria de vulneración de los derechos constitucionales.

Adicionalmente, en la misma disposición normativa se reconoce el tipo de reparaciones posibles, sin que sea una lista taxativa, lo cual es fruto de la recepción de estándares internacionales; así, expresamente se hace mención a las medidas de: restitución del derecho, compensación económica o patrimonial, rehabilitación, satisfacción, garantías de no repetición, obligación de investigar, medidas de reconocimiento, disculpas públicas, prestación de servicios públicos, atención de salud, entre otras. De manera que la restitio in integrum procure a las víctimas de las transgresiones a los derechos constitucionales un goce del derecho de la manera más adecuada posible y en la medida de lo posible se restablezca a la situación anterior de la violación, cuando aquello sea posible. 
Otra cuestión fundamental que debemos resaltar es aquella relacionada con la posibilidad que la reparación integral no surja exclusivamente de la decisión de un juez constitucional, dado que también puede ser resultado de un acuerdo reparatorio al que han llegado la persona víctima de un derecho constitucional y de quién transgredió el derecho, como otra de las formas de terminar el litigio jurisdiccional de protección de derechos. ${ }^{10}$

Frente a la existencia de la vulneración de derechos constitucionales se configuran varios elementos que se analizarán brevemente a continuación. El primero tiene que ver con la existencia de un sujeto titular del derecho sobre quien recae la vulneración y es considerado como víctima de la trasgresión, al igual que los individuos que le rodean y se sienten también afectados en sus derechos de manera directa o indirecta por el mismo acto. Este concepto de víctima ha sido desarrollado por la jurisprudencia de la Corte IDH ya que en un principio y desde una visión restrictiva se consideraba víctima únicamente a quien había sufrido directamente la vulneración, dejando a un lado a los familiares y personas cercanas del afectado sobre los cuales recaen también las consecuencias de los daños, ${ }^{11}$ con lo cual las víctimas pueden ser las directamente o indirectamente afectadas por la transgresión de los derechos constitucionales. La admisión de las víctimas indirectas implica la ampliación del ámbito de protección y por consiguiente de reparación.

El segundo elemento que conforma la reparación integral es la pretensión que persigue de restablecer el derecho, como finalidad idónea de esta que es expresada a través de la restitutio in integrum, institución que pretende devolver a la víctima al estado anterior a la producción del daño, siempre y cuando sea posible, como por ejemplo en el caso de reintegro de un trabajador a su puesto de trabajo. Es importante recalcar que cuando no es posible la retroacción de los sucesos que vulneraron el derecho, como ocurre en el caso de graves vulneraciones de derechos humanos, será necesaria la adopción de medidas alternativas o un conjunto de formas de reparación que puedan compensar el daño propiciado; sin embargo, la restitutio in integrum constituye el máximo ideal de la reparación integral, por cuanto define que devolver a la víctima a su estado anterior conforma la finalidad óptima de alcanzar la reparación integral.

En efecto, la imposibilidad de sustraer en su totalidad los efectos de la afección de los derechos genera la necesidad de acudir a las formas o medidas alternativas de reparación integral ya sean estas de naturaleza compensatoria o simbólica. Esta implementación de diferentes medidas de reparación ajustables a la magnitud de

10. Ecuador, Ley Orgánica de Garantías Jurisdiccionales y Control Constitucional, art. 15, numeral 2.

11. Corte Interamericana de Derechos Humanos, sentencia reparaciones y costas, Castillo Páez vs. Perú. 
vulneraciones, ${ }^{12}$ como lo demuestra el actual debate en Colombia sobre la implementación de la justicia transicional. ${ }^{13}$

La restitutio in integrum por la naturaleza de las afectaciones derivadas de una transgresión de un derecho constitucional debe ser interpretada de manera profunda, con lo cual no implica limitadamente el solo reconocimiento de la restitución del goce del derecho, ya que el restablecimiento debe comprender un goce material para que se ajuste a una reparación adecuada, debe desplegarse el derecho a los hechos. Entonces, es la naturaleza del conflicto y el tipo de afectaciones las que determinan las formas y alcances de la reparación integral.

El tercer elemento se refiere a la proporcionalidad, como el elemento que brinda equilibrio entre la afectación generada a los derechos y las medidas adoptadas en la decisión de reparación integral. La finalidad de la proporcionalidad de las medidas de reparación se funda principalmente en evitar su desnaturalización a través del enriquecimiento de la víctima por propiciarle una cuantiosa indemnización o la insatisfacción de la víctima al no cubrir adecuadamente el resarcimiento. La medición de los daños con base en la magnitud que comporta busca que ante mayores daños se debe aplicar mayores medidas de reparación y viceversa, con lo cual la proporcionalidad entonces exige la presencia del nexo causal y la estimación de los agravios para aplicar reparaciones proporcionales y adecuadas.

La proporcionalidad de las medidas de reparación es evaluada a partir de la motivación judicial. En efecto, la reparación integral, al ser objeto principal del proceso en el que se declaró la vulneración de un derecho constitucional, debe ser suficientemente justificada, razón por la cual inclusive la LOGJCC determina la posibilidad de realización de audiencias posteriores a la emisión de la sentencia para determinar las medidas proporcionales a la vulneración. ${ }^{14}$

Finalmente, el cuarto elemento de la reparación integral, emana de la responsabilidad asumida o condenada al transgresor del derecho que está obligado a resarcir el

12. "La reparación del daño requiere, siempre que sea posible, la plena restitución (restitutio in integrum), que consiste en el restablecimiento de la situación anterior. De no ser esto posible, como en el presente caso, el tribunal internacional debe determinar las medidas que garanticen los derechos conculcados, eviten nuevas violaciones y reparen las consecuencias que las infracciones produjeron, así como establecer la indemnización que compense por los daños ocasionados". Corte Interamericana de Derechos Humanos, sentencia excepciones preliminares, fondo, reparaciones y costas Tibi vs. Ecuador.

13. Cfr. Centro Internacional de Justicia Transicional, disponible en «https://www.ictj.org/es/que-es-la-justicia-transicional>. Consulta: 28 de junio de 2017. Véase también Justicia Transicional, disponible en 〈http://www.justiciatransicional.gov.co/Justicia-Transicional/Justicia-transicional-en-Colombia〉. Consulta: 28 de junio de 2017.

14. Ecuador, Ley Orgánica de Garantías Jurisdiccionales y Control Constitucional, art. 21. 
daño. En este sentido, la obligación que se deriva de la responsabilidad se convierte en el derecho de la víctima a ser resarcida por los daños inmateriales o materiales, por lo tanto, se convierte en un elemento clave de la reparación integral, en este caso, la responsabilidad personal cuando se tutela en el derecho interno de cada Estado, o internacional de los Estados a nivel internacional de protección de los derechos humanos.

\section{DISCURSO JURÍDICO DE LA CORTE CONSTITUCIONAL RESPECTO A LA REPARACIÓN INTEGRAL}

La Corte Constitucional del Ecuador, de acuerdo con lo dispuesto en el artículo 429 de la Constitución de la República, es el máximo órgano de la administración de justicia constitucional, razón por la cual surge su rol de custodio de los derechos, en la dimensión subjetiva (resolviendo las vulneraciones de derechos de los accionantes), así como en la dimensión objetiva (creando precedentes de obligatorio cumplimiento en la hermenéutica constitucional). Y es precisamente por el efecto multiplicador que genera la dimensión objetiva de las decisiones de la Corte Constitucional que la incorporación de estándares internacionales de los derechos humanos tiene especial importancia en el contenido progresivo que se le ha dado a la reparación integral y en consecuencia al goce de los derechos constitucionales. ${ }^{15}$ Para conocer los criterios de la Corte Constitucional respecto de este aspecto, se examinaron algunas sentencias que se emitieron entre 2008 y $2017,{ }^{16}$ las cuales permitirán dar cuenta de la dimensión real de la reparación integral.

A partir de la premisa que reconoce el derecho que posee toda persona a ser reparado cuando se le propicia un daño. Si se considera que la vulneración de un derecho implica el menoscabo a las facultades jurídicas de un sujeto, la sola vulneración de un derecho humano ya comporta un daño en sí mismo y según la naturaleza del conflicto se generan repercusiones en la vida jurídica, psicológica, económica y emocional del sujeto. Estos efectos constituyen las consecuencias de la vulneración de derechos de donde surge la necesidad de establecer la reparación integral en observación de los criterios de proporcionalidad para las diferentes afectaciones o daños materiales o

15. En este punto es importante señalar que el Ecuador ha ratificado la adhesión a la Convención Americana de Derechos Humanos (en adelante CADH) el 8 de diciembre de 1977, y aceptó la jurisdicción contenciosa de la Corte Interamericana de Derechos Humanos el 24 de julio de 1984 reconociendo la vigencia de los artículos 45 y 62 de la CADH, mediante Decreto No. 2768 publicado en el Registro Oficial No. 795 de 27 de julio de 1984.

16. Corte Constitucional del Ecuador, sistema de relatoría. Disponible en 〈https://www.corteconstitucional. gob.ec/index.php/casos-y-sentencias/casos-y-sentencias/relatoria.html). 
inmateriales padecidos por la víctima. Entonces, el deber de reparación, surge ante toda violación de derechos y su alcance está determinado por la medida de los daños. ${ }^{17}$

En esta línea, los objetivos básicos que deben estar inmersos en todas las medidas de reparación integral ordenadas deben estar dirigidas a: "1. Ayudar a las víctimas a mejorar su situación, a enfrentar las consecuencias de la violencia, reconociendo su dignidad como personas. 2. Mostrar solidaridad con las víctimas y un camino para restablecer su confianza en la sociedad y las instituciones". ${ }^{18}$

Finalmente, vale señalar que las decisiones analizadas corresponden a criterios en los cuales la Corte ha desarrollado algún punto relevante de la reparación integral desde los inicios de la jurisprudencia de la Corte Constitucional para el período de transición, pasando por la primera Corte Constitucional y la actual composición. Esto de conformidad con el artículo 432 y 25 del Régimen de Transición de la Constitución de la República del Ecuador, en concordancia con las disposiciones transitorias sexta, séptima, octava y novena de la Ley Orgánica de Garantías Jurisdiccionales y Control Constitucional.

\section{Período comprendido entre 2008 y 2009}

En este primer período la Corte Constitucional para el período de transición, no se pronunció con respecto a los contenidos que integran el derecho a la reparación integral. Lo hace de manera circunstancial, ordenando el cumplimiento de las resoluciones del antiguo Tribunal Constitucional. ${ }^{19}$ Esta forma de "reparar" estará presente a lo largo de este período, pues se repite este patrón. ${ }^{20}$ En otras decisiones la Corte señala que la reparación integral implica cumplir la sentencia, pues solo allí finaliza el proceso judicial y que aquella debe ser la encargada de velar por su cumplimiento; ${ }^{21}$ o en otras se establece a la restitución como un elemento de la reparación integral. ${ }^{22}$

17. Corte Interamericana de Derechos Humanos, La Corte Interamericana de Derechos Humanos, un cuarto de siglo: 1997-2004 (San José, C.R., 2005).

18. Carlos Martín Beristaín, Diálogos sobre la reparación. Experiencias en el sistema interamericano de derechos humanos (San José de Costa Rica: Instituto Interamericano de Derechos Humanos/Agencia Sueca de Cooperación Internacional para el Desarrollo, 2008), 11.

19. Corte Constitucional del Ecuador, sentencia No. 0001-09-SIS-CC.

20. Corte Constitucional del Ecuador, sentencias: 0006-109-SIS-CC; 0007-09-SIS-CC; 0008-09-SIS-CC; 0009-09-SIS-CC; 0014-09-SIS-CC.

21. Corte Constitucional del Ecuador, sentencias: 0004-09-SIS-CC; 0005-09-SIS-CC.

22. Corte Constitucional del Ecuador, sentencia No. 0012-09-SIS-CC. 
Por otro lado, cuando la Corte conoció acciones extraordinarias de protección, dispuso, por ejemplo, el acceso a la información pública, ${ }^{23}$ así como que otras instituciones adopten las medidas necesarias para examinar la conducta de un juez, ${ }^{24}$ ampliándose el espectro del ámbito decisorio del juez.

Finalmente, la Corte en materia de control constitucional, en el dictamen que señaló la compatibilidad del Convenio Internacional para la Protección de Todas las Personas contra las Desapariciones Forzadas con la Constitución, se refirió a la reparación integral en el sentido de que la Asamblea Nacional debía tipificar la desaparición forzada de personas conminándola para que cumpla con su obligación; ${ }^{25} \mathrm{y}$, en una sentencia interpretativa, dispuso que se inscriba en un Registro de la Propiedad una declaratoria de utilidad pública. ${ }^{26}$

\section{Período 2010}

El patrón establecido en 2009 se mantiene en 2010. En efecto, la Corte, principalmente al conocer acciones de incumplimiento con respecto a las resoluciones del antiguo Tribunal Constitucional, siguió ordenando el pago de haberes, la restitución a cargos, reliquidaciones, así como disponiendo se inicien investigaciones en contra de quienes obstaculizaron el cumplimiento de sus decisiones; ${ }^{27}$ en otras ordenó el registro de títulos, el reintegro de trabajadores en otras escalas laborales, la revocatoria de medidas cautelares, la reforma de plazos para la convocatoria a concursos de méritos, la inscripción en un Registro de la Propiedad de la titularidad de un predio a favor del Estado, así como la destitución varios servidores públicos, o que el Banco Central ubique una partida presupuestaria para el cumplimiento de su decisión. ${ }^{28}$

En varias de las referidas decisiones se señaló, además, que se deben procurar los "medios" para que las reparaciones sean cumplidas, adoptando como sinónimas la "aplicación integral de la sentencia" con la "reparación", señalando que la reparación integral es un derecho por lo que se debe analizar la resolución "para la realización de

23. Corte Constitucional del Ecuador, sentencia No. 0019-09-SIS-CC.

24. Corte Constitucional del Ecuador, sentencia No. 0031-09-SIS-CC.

25. Corte Constitucional del Ecuador, sentencia No. 0006-09-DTI-CC.

26. Corte Constitucional del Ecuador, sentencia No. 0002-09-SIC-CC.

27. Corte Constitucional del Ecuador, sentencias: 003-10-SIS-CC; 036-10-SIS-CC; 015-10-SIS-CC; 019-10-SIS-CC.

28. Corte Constitucional del Ecuador, sentencias: 001-10-SIS-CC; 003-10-SIS-CC; 020-10-SIS-CC; 022-10-SIS-CC; 031-10-SIS-CC. 
la justicia"; en otras decisiones, se ordenaron medidas para dejar sin efecto una orden "por ser un asunto de mera legalidad". ${ }^{29}$

En las decisiones sobre acciones extraordinarias de protección la Corte dispuso mayoritariamente dejar sin efecto la decisión impugnada, como consecuencia de la verificación de la vulneración de un derecho. ${ }^{30}$

Finalmente, en la sentencia de jurisprudencia vinculante No. 001-10-PJO-CC, en la que por primera vez se dictaron explícitamente reglas jurisprudenciales se señaló que:

45.- En armonía con la lógica del Estado Constitucional de derechos y justicia, la Constitución vigente dispone expresamente en su artículo 86 numeral 3 que: 'los procesos judiciales solo finalizarán con la ejecución integral de la sentencia o resolución'. En virtud de dicho precepto se desprende que un proceso constitucional no finaliza con la expedición de la sentencia o resolución; por el contrario, lo trascendental es el cumplimiento de la misma, su eficacia normativa, efecto jurídico que permite la materialización de la reparación integral.

Esta decisión es un hito en el constitucionalismo ecuatoriano dado que la Corte Constitucional, a partir de una interpretación integral, determinó que la acción de incumplimiento de sentencias y dictámenes constitucionales es una verdadera garantía jurisdiccional de derechos. ${ }^{31}$

\section{Período comprendido entre 2011 y 2012}

En 2011 no existen mayores novedades, salvo una un poco marginal: en las decisiones tomadas en los procesos de acciones extraordinarias de protección, pese a que en ellas es común dejar sin efecto las sentencias de jueces a quo, se menciona que ello

29. Corte Constitucional del Ecuador, sentencias: 012-10-SIS-CC; 015-10-SIS-CC; 022-10-SIS-CC.

30. Corte Constitucional del Ecuador, sentencias: 002-10-SEP-CC; 029-10-SEP-CC.

31. “49.- El mecanismo de cumplimiento de sentencias propende a la materialización de la reparación integral adoptada dentro de una garantía jurisdiccional. La Corte Constitucional, de oficio o a petición de parte, considerando que de por medio se encuentra la materialización de la reparación integral, y sin necesidad de que comparezca exclusivamente el afectado, está en la obligación de velar por el cumplimiento de las sentencias constitucionales.

[...] 3.2. Considerando que el mecanismo de cumplimiento de sentencias propende a la materialización de la reparación integral adoptada dentro de una garantía jurisdiccional, la Corte Constitucional, de oficio o a petición de parte, considerando que de por medio se encuentra la materialización de la reparación integral, y sin necesidad de que comparezca exclusivamente el afectado, está en la obligación de velar por el cumplimiento de las sentencias constitucionales". 
constituye reparación integral. ${ }^{32}$ En otras, se adoptaron medidas como la orden de conferir una condecoración, o el señalar que si una persona se benefició de la sentencia de un divorcio no puede impugnarla, o que la forma de garantizar la reparación integral del derecho constitucional vulnerado es dejando sin efecto la sentencia dictada. ${ }^{33}$

En las decisiones de acciones de incumplimiento se señaló que la aplicación integral de la sentencia implica su ejecución o reparación integral, que esta es un deber y una obligación, ya que los procesos solo terminan con la aplicación integral de la sentencia o reparación. ${ }^{34}$ También se señaló que, si la sentencia que se demanda incumplida no establece pago alguno, aun así la reparación de haberes dejados de percibir es procedente, que los tribunales de conciliación y arbitraje deben practicar otra liquidación, o que se debe reintegrar a trabajadores a las funciones que venían desempeñando. ${ }^{35}$

\section{Período COMPRendido entre el 2012 al 2017}

Es importante señalar que con la entrada en vigencia de la Constitución de 2008, como no pudo ser de otra forma, trajo consigo un período de transición, el cual culminó para la justicia constitucional el 6 de noviembre de 2012, fecha en la que se posesionaron los jueces de la Corte Constitucional que resultaron elegidos del proceso determinado en la Constitución y LOGJCC. También es de destacar que es en este período en el que la Corte Constitucional ha dictado decisiones relevantes en materia de reparación integral y sobre todo en la recepción de los estándares internacionales, así dentro de las decisiones hito tenemos:

1. En la sentencia No. 0001-13-SAN-CC se determinó que la reparación integral se encuentra en comunión con el modelo de Estado que tiene actualmente el Ecuador, el que señala el valor justicia como el estándar apropiado para el cumplimiento de derechos; esta decisión se torna en fundamental dado que la Corte Constitucional expresamente señala que la reparación debe ser considerada en su integralidad más allá de los criterios económicos:

En efecto, una revisión panorámica de la Constitución nos remite a los artículos: 11 numeral 9, que determina que el más alto deber del Estado consiste en respetar y hacer respetar

32. Corte Constitucional del Ecuador, sentencias: 045-11-SEP-CC; 048-11-SEP-CC.

33. Corte Constitucional del Ecuador, sentencias: 024-11-SEP-CC; 026-11-SEP-CC; 043-11-SEP-CC.

34. Corte Constitucional del Ecuador, sentencias: 002-11-SIS-CC; 009-11-SIS-CC; 027-11-SIS-CC.

35. Corte Constitucional del Ecuador, sentencias: 021-11-SIS-CC; 009-11-SIS-CC; 010-11-SIS-CC. 
los derechos garantizados en la Constitución; y el artículo 86 numeral 3 que señala que en materia de las garantías jurisdiccionales, el juez resolverá la causa en sentencia, y en caso de constatar vulneración de derechos, deberá declararla, ordenando reparación integral, material e inmaterial, y especificar la individualización de las obligaciones, positivas y negativas, a cargo del destinatario de la decisión judicial y las circunstancias como deba cumplirse. De esto se puede colegir que existe una amplia recepción del principio de reparación integral del sistema internacional de los derechos humanos en la Constitución ecuatoriana, que tiene sentido junto al modelo de Estado que incluye el valor justicia en proscripción de la impunidad.

La Corte Constitucional determinó que la rebaja de pena es uno de los instrumentos que permiten la reinserción adecuada de las personas privadas de la libertad a la sociedad, a través de la participación activa y directa en los procesos de rehabilitación que se producen en los centros penitenciarios. Sobre la base de la verificación de la vulneración de derechos constitucionales del accionante señaló tres medidas de reparación.

La primera medida de reparación comportó una garantía de no repetición a favor de las personas que se encuentran internas en los centros de rehabilitación social, precisando que la obligación de abrir el expediente, conforme la normativa pertinente, es el momento del ingreso del interno al centro. Señaló también que esta obligación debe ser acatada por los directores de los centros de rehabilitación social; y la supervisión de esta medida se encomendó a la Defensoría del Pueblo.

La segunda medida de disculpas públicas tiene un carácter simbólico y establece que la institución encargada de la rectoría de los Centros de Rehabilitación Social -Ministerio de Justicia- y el director del centro penitenciario en el que el accionante cumplió su pena le ofrezcan disculpas públicas por el incumplimiento de la norma legal, las cuales se realizaron en uno de los diarios de mayor circulación nacional.

Finalmente, la tercera medida, deber de investigar, está relacionada con la obligación del Ministerio de Justicia de indagar y sancionar a los responsables del desconocimiento de la norma infraconstitucional. Como se puede observar, esta decisión es un claro ejemplo de la recepción de los estándares interamericanos sobre la reparación integral y de entenderla como una verdadera restito in integrum.

2. En la sentencia No. 004-13-SAN-CC la Corte Constitucional determinó que la forma de realizar el cálculo concerniente a la reparación económica como parte de la reparación integral tiene que hacerse de manera célere, que el procedimiento determi- 
nado en el artículo 19 de la LOGJCC ${ }^{36}$ es constitucional siempre que sea entendido como un proceso de ejecución, razón por la cual la Corte Constitucional declaró inconstitucional la posibilidad de presentar recursos de casación en dichos procedimientos. Posteriormente, frente a los problemas advertidos por la Corte Constitucional en el proceso de seguimiento de sentencias y dictámenes constitucionales, esta dictó reglas de cómo debían sustanciarse estos procedimientos mediante la sentencia No. 0011-16-SIS-CC, con lo cual, en los dos casos dictó medidas de no repetición.

Estas sentencias se convierten en precedentes jurisprudenciales que reafirman el derecho a la reparación integral sin considerar como presupuesto la gravedad o atrocidad de los hechos, razón por la cual se afirma que la reparación integral brinda cobertura a todos los casos en los que existan daños por vulneración de derechos, siendo el punto de equilibrio la proporcionalidad de las medidas de reparación adoptadas en relación al daño ocasionado.

3. La Corte Constitucional, al emitir la sentencia No. 080-13-SEP-CC, ${ }^{37}$ resolvió acerca de un presunto acto discriminatorio en contra de una persona portadora de VIH por parte de una entidad estatal que culminó con la destitución. La Corte inició su análisis estableciendo que la Constitución en el artículo 11 número 2 consagra el derecho de las personas a no ser discriminadas por ningún motivo, especialmente por las denominadas "categorías sospechosas", es decir, aquellos criterios que a priori se consideran discriminatorios a menos que se demuestre lo contrario, debido a que usualmente tienden a generar exclusión.

Como sustento de los criterios de la Corte, se cita la opinión consulta No. 18/03 emitida por la Corte Interamericana de Derechos Humanos, atinente a la obligación de los Estados de adoptar medidas positivas para revertir las prácticas discriminatorias existentes en las sociedades en perjuicio de determinados grupos de personas. $\mathrm{La}$ Corte Constitucional decidió entonces que la destitución del accionante se tradujo en un acto discriminatorio, razón por la cual dictó una medida de restitución de su puesto de trabajo, así como la correspondiente medida de compensación económica y en atención a la responsabilidad estatal de adoptar medidas de protección para las perso-

36. “Art. 19.- Reparación económica.- Cuando parte de la reparación, por cualquier motivo, implique pago en dinero al afectado o titular del derecho violado, la determinación del monto se tramitará en juicio verbal sumario ante la misma jueza o juez, si fuere contra un particular; y en juicio contencioso administrativo si fuere contra el Estado. De estos juicios se podrán interponer los recursos de apelación, casación y demás recursos contemplados en los códigos de procedimiento pertinentes".

37. Corte Constitucional del Ecuador, sentencia No. 080-13-SEP-CC. 
nas de los grupos de atención prioritaria, dicto tres reglas inter pares e inter comunis, como garantía de no repetición.

4. En la decisión constitucional constante en la sentencia No. 004-14-SCN-CC, relativa a la consulta de norma presentada por un juez de la Amazonía a la Corte Constitucional dentro de la causa penal iniciada a varias personas pertenecientes al pueblo indígena Waorani - de reciente contacto- por el supuesto genocidio cometido en contra del pueblo indígena Taromenane -no contactado-. La Corte Constitucional analizó la norma jurídica consultada a la luz del principio de diversidad étnico cultural de los pueblos de reciente contacto, sobre la base del artículo 57 de la Constitución que consagra la obligación del Estado de adoptar medidas para garantizar la vida de los pueblos en aislamiento voluntario, hacer respetar su autodeterminación y la voluntad de permanecer en aislamiento y precautelar sus derechos; y con base en lo dispuesto en los artículos 8, 9 y 10 del Convenio 169 de la OIT.

A partir de este examen la Corte Constitucional concluyó que, en el caso concreto, existía un "error de comprensión culturalmente condicionado" por el que debía garantizarse la no aplicación de la norma penal cuando se demuestre que uno o varios de los miembros de una comunidad, pueblo o nacionalidad indígena que supuestamente perpetró un ilícito, se encontraba en una situación que les impedía conocer la norma penal. Lo más relevante en este caso es que la Corte Constitucional determinó como garantía de no repetición la siguiente regla interpretativa:

De conformidad con artículo 143 numeral 2 de la Ley Orgánica de Garantías Jurisdiccionales y Control Constitucional, la figura penal del genocidio solo podrá ser aplicada en el caso concreto por el juez consultante, siempre que se verifique de manera argumentada el cumplimiento de todos y cada uno de los presupuestos convencionales determinados en la "Convención para la Prevención y la Sanción del Delito de Genocidio", todo ello en observancia a los parámetros de interculturalidad, en los términos previstos en esta decisión.

5. Respecto al derecho a la verdad, la Corte Constitucional en la sustanciación de una acción extraordinaria de protección presentada en contra de un sobreseimiento definitivo emitió la sentencia No. 114-14-SEP-CC, en la cual se señaló que el derecho a la verdad se orienta a garantizar a las víctimas o a sus familiares la reparación en función del reconocimiento por parte de las autoridades competentes de la responsabilidad en la falta de investigación de vulneraciones a derechos y/o falta de aplicación de las sanciones que legalmente correspondan. En este caso la Corte Constitucional se basó en el análisis convencional de lo resuelto por la Corte Interamericana de Derechos Humanos en los casos Velásquez vs. Honduras; González Medina y familiares 
vs. República Dominicana; y Gelman vs. Uruguay; concluyendo que había faltas graves en la etapa de investigación del proceso penal.

6. Dentro de las medidas de rehabilitación ordenas por la Corte Constitucional se puede citar la sentencia No. 016-16-SEP-CC, en la que la Corte determinó que la destitución de un Policía Nacional sin considerar su situación de VIH comportaba un trato discriminatorio; en consecuencia, la Corte dispuso como medida de rehabilitación, entre otras, la siguiente:

3.2.1 Que las autoridades correspondientes, según la normativa interna de la Policía Nacional, asuman la responsabilidad de la prestación de servicios médicos al accionante, incluidos los tratamientos psicológicos (para él y su familia), y tratamientos físicos integrales que requiera así como de la entrega de medicinas necesarias para atender su condición y demás situaciones médicas que ocurran por ser portador de VIH, para lo cual adoptará las medidas necesarias para su cumplimiento, ya sea en el ámbito médico privado o de la propia institucionalidad médica de la Policía Nacional.

7. Respecto a derechos de género, la Corte ha sido enfática en aplicar criterios convencionales, específicamente la Convención de Belem do Para y la sentencia de la Corte IDH de Campo Algodonero; así se puede citar la sentencia No. 292-16-SEP-CC que declaró la vulneración del derecho a la igualdad de la accionante y no discriminación disponiendo, entre otras, como medidas de reparación integral, las disculpas públicas y la restitución de su derecho, específicamente tener la oportunidad de regresar a su puesto de trabajo.

8. En la sentencia No. 074-16-SIS-CC, el representante de un grupo de niños y niñas solicitó la tutela del derecho a la salud, por ser diagnosticados con una enfermedad rara. En este caso la Corte Constitucional, a partir de la declaración de la vulneración de los derechos de los accionantes, dispuso la provisión del servicio de salud, atención médica y entrega de medicamentos como medidas de reparación integral. ${ }^{38}$

38. “c. En razón del efecto inter comunis de la presente sentencia, que el representante del Ministerio de Salud Pública, una vez iniciado el trámite de registro sanitario del medicamento INCRELEX, proceda con el suministro del mismo a los niños y niñas que cuenten con el consentimiento informado de sus representantes legales y que previa certificación del Ministerio de Salud Pública acrediten el padecimiento de la enfermedad denominada 'Síndrome de Laron'. El cumplimiento de esta medida deberá ser informado periódicamente a este organismo.

d. Que el representante del Ministerio de Finanzas asigne los recursos económicos correspondientes al 
9. Finalmente, respecto de la tutela del derecho a la identidad sexual, determinado en la sentencia No. 133-17-SEP-CC, la Corte Constitucional dictó como medida de rehabilitación que "la Dirección General de Registro Civil, Identificación y Cedulación margine en la inscripción de nacimiento del señor [...], el cambio de sexo de femenino a masculino. El representante de la Dirección General de Registro Civil, Identificación y Cedulación deberá informar documentadamente a esta Corte Constitucional en el término de 20 días desde la notificación de la sentencia, respecto a las acciones tendientes al cumplimiento de la presente medida".

De la evolución jurisprudencial se puede inferir que la Corte Constitucional ha generado medidas de reparación integral y no meras compensaciones económicas, desarrollando distintas medidas de reparación integral, las cuales encuentran su origen en la naturaleza y patrones fácticos del conflicto que representan las vulneraciones de derechos constitucionales, entendiéndose que el conjunto de medidas alternativas de reparación integral que hoy conocemos, como las disculpas públicas, rehabilitación, garantías de no repetición, entre otras, han sido diseñadas en relación directamente proporcional a los grados de afectación y gravedad que soportaron los casos.

En efecto, de los casos expuestos, se evidencian medidas de reparación de naturaleza simbólica y de alcance profundo -medidas materiales e inmateriales-; asimismo es posible identificar que la naturaleza de los conflictos que las determinan corresponde a vulneraciones que afectan directamente al derecho a la vida, vida digna, igualdad, entre otros derechos.

La especial atención a la reparación de la víctima en función a las prioridades particulares representa sensibilización de la justicia restaurativa y el interrelacionamiento entre diferentes mecanismos de reparación de carácter material e inmaterial, que demandan la necesidad de coherencia entre todas las medidas dispuestas. Ciertamente, no pueden analizarse aisladamente las medidas, sino como un conjunto de acciones destinado a restituir los derechos de las víctimas y proporcionar a los beneficiarios suficientes elementos para mitigar la afectación producida por las violaciones, promover su rehabilitación y compensar las pérdidas.

\section{REFLEXIONES FINALES}

Desde el punto de vista normativo constitucional y jurisprudencial, y en menor grado en la Ley Orgánica de Garantías Jurisdiccionales y Control Constitucional vi-

Ministerio de Salud Pública, para efectos de la adquisición continua del medicamento INCRELEX. El cumplimiento de esta medida deberá ser informado trimestralmente a este organismo". 
gente, el déficit y problemas que experimentaron las garantías constitucionales reconocidas en la Constitución Política de 1998, principalmente en su diseño y desarrollo en la Ley del Control Constitucional de la época como en la jurisprudencia que dictaba el entonces Tribunal Constitucional, han sido en muchos casos subsanados y otros atenuados, reconociendo, claro está, que aún resta mucho por hacer para garantizar la eficacia de las garantías y por tanto la materialización de un concepto claro y garantista de reparación integral.

La jurisprudencia constitucional emitida por la Corte Constitucional del Ecuador da cuenta de un importante desarrollo del concepto y alcance de la reparación integral. Las decisiones aquí analizadas demuestran la recepción de estándares internacionales de protección de derechos humanos en lo que respecta a mecanismos que van más allá de la mera compensación económica, dotando de eficacia al derecho de reparación integral individual, por ejemplo, a partir del otorgamiento de medidas de satisfacción, rehabilitación, compensación, como derecho colectivo, a partir de la incorporación de medidas de no repetición.

También resulta interesante advertir cómo la jurisprudencia de la Corte Constitucional ha materializado el concepto de reparación integral independientemente del derecho constitucional que se declaró como vulnerado. Esto evidencia que existe un importante desarrollo en torno a la igualdad jerárquica y la justiciabilidad directa de todos los derechos constitucionales, sean estos derechos de libertad, protección, participación, o buen vivir. Esta protección se ha materializado a través de medidas de reparación integral que han tenido incluso repercusiones en el presupuesto estatal a fin de garantizar el pleno ejercicio de los derechos, de esta forma se denota que es la dignidad humana el objeto central de tutela.

También llama la atención cómo la Corte ha construido importantes criterios respecto a las medidas de reparación inmaterial; es el caso, por ejemplo, de las disculpas públicas, la difusión de las sentencias en los portales web de las entidades obligadas, como medidas de satisfacción; las cuales ciertamente deben servir como referentes para los casos que diariamente conocen los jueces constitucionales del país.

La jurisprudencia constitucional, en tanto fuente sociológica del Derecho, da cuenta de los avances y problemas que enfrenta la reparación integral en la tutela de los derechos. Por ello desde ahí debemos emprender estudios críticos propositivos para iniciar un verdadero debate respecto a la eficacia de los derechos constitucionales. 


\section{BIBLIOGRAFÍA}

Aguirre Castro, Pamela. "El control de convencionalidad y sus desafíos en el Ecuador". Revista del Instituto Interamericano de Derechos Humanos (IIDH), No. 64. Disponible en 〈http://www.iidh.ed.cr/iidh/media/4759/revista-64-2web.pdf〉.

—, Dayana Ávila y Alfredo Ruiz, edit. Desarrollo Jurisprudencial de la Primera Corte Constitucional. Quito: Corte Constitucional del Ecuador, Secretaría Técnica Jurisdiccional de la Corte Constitucional del Ecuador, 2016.

Aguirre Castro, Pamela, edit. Una lectura cuantitativa y cualitativa de las decisiones del Tribunal Constitucional a la primera Corte Constitucional. Quito: Corte Constitucional del Ecuador/Centro de Estudios y Difusión del Derecho Constitucional (CEDEC), 2015.

Alarcón Peña, Pablo. La ordinarización de la acción de protección. Quito: Universidad Andina Simón Bolívar, Sede Ecuador/Corporación Editora Nacional, 2013.

—. "La protección de los derechos sociales en la jurisprudencia constitucional ecuatoriana". En Christian Courtis y Ramiro Ávila, edit., La protección judicial de los derechos sociales. Quito: Ministerio de Justicia y Derechos Humanos, 2009.

Asamblea General de las Naciones Unidas. Resolución 60/147, 16 de diciembre de 2005.

Ávila Santamaría, Ramiro. "El amparo constitucional entre el diseño liberal y la práctica formal". En Un cambio ineludible: La Corte Constitucional. Quito: Tribunal Constitucional del Ecuador, 2007.

Bidart Campos, Germán J. Teoría general de los derechos humanos. México D. F.: UNAM, 1989.

Corte Interamericana de Derechos Humanos. La Corte Interamericana de Derechos Humanos, un cuarto de siglo: 1997-2004. San José, 2005.

Martín Beristaín, Carlos. Diálogos sobre la reparación. Experiencias en el sistema interamericano de derechos humanos. San José de Costa Rica: Instituto Interamericano de Derechos Humanos/Agencia Sueca de Cooperación Internacional para el Desarrollo, 2008.

Miranda, Javier. "Enfoques de Naciones Unidas sobre Impunidad y Reparación”. En Verdad y Justicia en procesos de paz o transición a la democracia, Memorias. Bogotá: Oficina en Colombia del Alto Comisionado de las Naciones Unidad para los Derechos Humanos/Comisión Colombiana de Juristas/Fundación Social/Programa por la Paz-Compañía de Jesús, 2003.

Storini, Claudia, y Marco Navas. La acción de protección en Ecuador: realidad jurídica y social. Quito: Corte Constitucional del Ecuador, 2013.

Valle Franco, Alex. El amparo como garantía constitucional en el Ecuador. Quito, Universidad Andina Simón Bolívar, Sede Ecuador/Corporación Editora Nacional, 2012.

Van Boven, Theo. "Principios y directrices básicos de las Naciones Unidas sobre el derecho de las víctimas de violaciones manifiestas de las normas internacionales de derechos humanos y de violaciones graves del Derecho Internacional Humanitario a interponer recursos y ob- 
tener reparaciones”. Disponible en 〈http://legal.un.org/avl/pdf/ha/ga_60-147/ga_60-147_s. pdf〉.

Zagrebelsky, Gustavo. El derecho dúctil. Madrid: Trotta, 1995.

\section{Cuerpos normativos}

Constitución de la República del Ecuador. 2008.

Constitución Política de la República del Ecuador. 1998.

Convención Americana de Derechos Humanos. 1978.

Ley de Control Constitucional. 1997.

Ley Orgánica de Garantías Jurisdiccionales y Control Constitucional. 2009.

\section{Corte Interamericana de Derechos Humanos}

Sentencia excepciones preliminares, fondo, reparaciones y costas, Tibi vs. Ecuador.

Sentencia excepciones preliminares, fondo, reparaciones y costas, González y otras (Campo Algodonero) vs. México.

Sentencia reparaciones y costas, Castillo Páez vs. Perú.

\section{Corte Constitucional del Ecuador}

Sentencia No. 0001-09-SIS-CC.

Sentencia No. 0006-09-SIS-CC.

Sentencia No. 0007-09-SIS-CC.

Sentencia No. 0008-09-SIS-CC.

Sentencia No. 0009-09-SIS-CC.

Sentencia No. 0014-09-SIS-CC.

Sentencia No. 0004-09-SIS-CC.

Sentencia No. 0005-09-SIS-CC.

Sentencia No. 0012-09-SIS-CC.

Sentencia No. 0019-09-SIS-CC.

Sentencia No. 0031-09-SIS-CC.

Sentencia No. 0006-09-DTI-CC.

Sentencia No. 0002-09-SIC-CC.

Sentencia No. 003-10-SIS-CC.

Sentencia No. 036-10-SIS-CC.

Sentencia No. 015-10-SIS-CC. 
Sentencia No. 019-10-SIS-CC.

Sentencia No. 001-10-SIS-CC.

Sentencia No. 003-10-SIS-CC.

Sentencia No. 020-10-SIS-CC.

Sentencia No. 022-10-SIS-CC.

Sentencia No. 031-10-SIS-CC.

Sentencia No. 012-10-SIS-CC.

Sentencia No. 015-10-SIS-CC.

Sentencia No. 022-10-SIS-CC.

Sentencia No. 002-10-SEP-CC.

Sentencia No. 029-10-SEP-CC.

Sentencia No. 001-10-PJO-CC.

Sentencia No. 045-11-SEP-CC.

Sentencia No. 048-11-SEP-CC.

Sentencia No. 024-11-SEP-CC.

Sentencia No. 026-11-SEP-CC.

Sentencia No. 043-11-SEP-CC.

Sentencia No. 002-11-SIS-CC.

Sentencia No. 009-11-SIS-CC.

Sentencia No. 027-11-SIS-CC.

Sentencia No. 021-11-SIS-CC.

Sentencia No. 009-11-SIS-CC.

Sentencia No. 010-11-SIS-CC.

Sentencia No. 001-13-SAN-CC.

Sentencia No. 004-13-SAN-CC.

Sentencia No. 080-13-SEP-CC.

Sentencia No. 004-14-SCN-CC.

Sentencia No. 114-14-SEP-CC.

Sentencia No. 0011-16-SIS-CC.

Sentencia No. 016-16-SEP-CC.

Sentencia No. 292-16-SEP-CC.

Sentencia No. 074-16-SIS-CC.

Sentencia No. 133-17-SEP-CC. 